\title{
TWO-PHASE REFRIGERANT DISTRIBUTION IN A PARALLEL FLOW MINICHANNEL HEAT EXCHANGER HAVING LOWER COMBINING/DIVIDING HEADER
}

\author{
Byun H.W. ${ }^{1}$, Kim O.J. ${ }^{1}$ and Kim N.H. ${ }^{2} *$ \\ ${ }^{1}$ Department of Extreme Thermal Systems, Korea Institute of Machinery \& Materials, \\ Korea \\ ${ }^{2}$ School of Mechanical System Engineering, Incheon National University, \\ Korea, \\ E-mail: knh0001@inu.ac.kr
}

\begin{abstract}
Brazed aluminum heat exchangers are recently considered as evaporators of automotive or residential air conditioners. In this case, it is very important to distribute the two-phase refrigerant (especially the liquid) evenly into each tube. In this study, R-410A distribution in a two pass evaporator with upper horizontal combining-dividing header was investigated. Tubes were heated to yield a test section outlet superheat of $5^{\circ} \mathrm{C}$ with inlet quality of 0.2 . The number of tubes was 10 for the inlet pass and 12 or 14 for the outlet pass. For each case, mass flux was varied from $73 \mathrm{~kg} / \mathrm{m}^{2} \mathrm{~s}$ to $143 \mathrm{~kg} / \mathrm{m}^{2} \mathrm{~s}$. In the combining/dividing header, two-phase mixture out of the inlet pass is first merged and then re-distributed to the outlet pass. More liquid is forced downstream as mass flux or quality increases yielding better flow distribution. Effect of insertion device in the inlet header was also investigated. Efforts were made to develop correlations to predict the liquid or gas distribution in a header with limited success. Header pressure drop data are also provided.
\end{abstract}

\section{INTRODUCTION}

Brazed aluminum heat exchangers, which consist of flat minichannel tubes on the refrigerant-side and louver fins on the air-side, have long been used as condensers of automotive air conditioners due to superior thermal performance as compared with conventional fin-and-tube heat exchangers. Brazed aluminum heat exchangers may be categorized as parallel flow heat exchangers because a number of tubes are grouped to one pass using a header, and form a parallel flow configuration. Typical hydraulic diameter of the flat tube is $1 \sim 2 \mathrm{~mm}$.

Recently, brazed aluminum heat exchangers are considered as evaporators of automotive or residential air conditioners. In this case, it is very important to distribute the two-phase refrigerant (especially the liquid) evenly into each tube. Otherwise, the thermal performance is significantly deteriorated. According to Kulkarni et al. [1], the performance reduction by flow mal-distribution could be as large as $20 \%$. The most of the studies on two-phase distribution in a header-branch configuration have been conducted on a single pass configuration [Fig. 1 (a)]. For a single pass configuration, refrigerant is divided into channels at the inlet header (dividing header), and is combined at the exit header (combining header).
Webb and Chung [2], Hrnjak [3], Lee [4], Ahmad et al. [5] provided recent reviews on this subject. For multi-pass configuration, refrigerant is first divided into channels at the inlet header of the first pass. Refrigerant out of the first pass is combined, delivered downstream and then divided into channels in the header (combining/dividing header) of the second pass. The process continues to the last exit header. It is expected that flow distribution characteristics in the combiningdividing header will be significantly different from that in the dividing header. However, literature shows very limited investigations on refrigerant distribution in combining/dividing header.

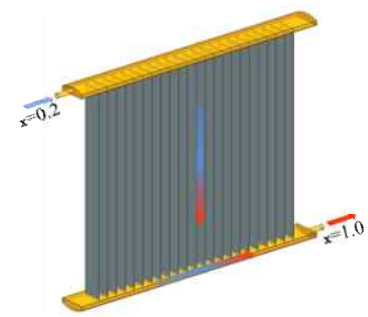

(a) one pass

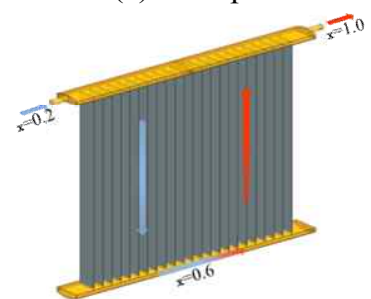

(b) two pass

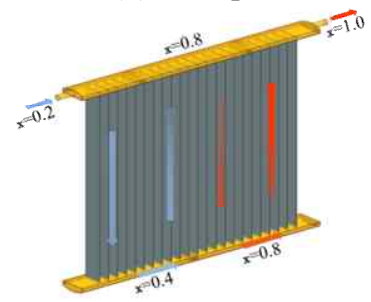

(c) four pass

Figure1Refrigerant-side circuiting (one, two and four pass) investigated in this study 
In this study, R-410A distribution in a two pass evaporator with upper horizontal combining/dividing header (and consequently inlet and outlet located at lower header as shown in Fig. 1) was investigated. Tubes were heated to yield a test section outlet superheat of $5^{\circ} \mathrm{C}$ with inlet quality of 0.2 . For each case, mass flux was varied from $73 \mathrm{~kg} / \mathrm{m}^{2} \mathrm{~s}$ to $143 \mathrm{~kg} / \mathrm{m}^{2} \mathrm{~s}$. The effect of insertion device located at lower inlet header on flow distribution was also investigated.

\section{EXPERIMENTS}

The same apparatus of Kim et al. [6] and Kim and Byun [7] was used, and one may consult those papers for further details. A schematic drawing of the experimental apparatus is shown in Fig. 2. Detailed drawing of the test section is shown in Fig. 3. The test section consists of the $17 \mathrm{~mm}$ I.D. round upper and lower headers, which are $91 \mathrm{~cm}$ apart, and flat tubes inserted at $9.8 \mathrm{~mm}$ pitches. Refrigerant was supplied from one side of upper header, combined/divided at lower header, and exited from opposite side of the upper header. At inlet of the test section, refrigerant was supplied through copper tube having smaller inner diameter $(7.92 \mathrm{~mm})$ than that of the header. At outlet of the test section, copper tube with $11.1 \mathrm{~mm}$ I.D. was used. The tube diameters were chosen to simulate an actual parallel flow evaporator.

The headers were made from transparent PVC rods for flow visualization. A $17 \mathrm{~mm}$ round hole was machined longitudinally in a square $(60 \mathrm{~mm} \times 55 \mathrm{~mm}) \mathrm{PVC}$ rod with flat holes machined at the bottom of the rod for insertion of flat tubes. An aluminum plate, which had matching flat holes, was

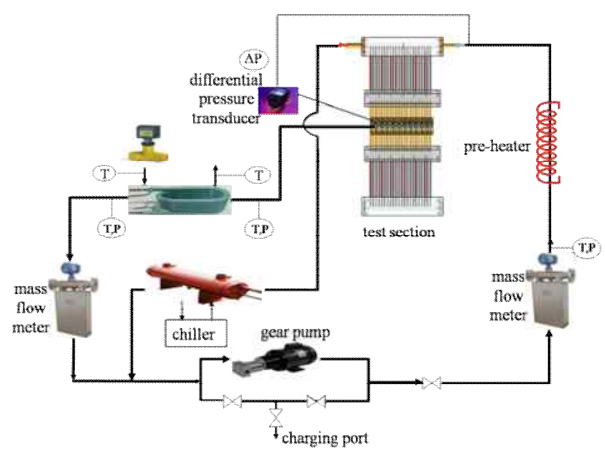

Figure2 Schematic drawing of the experimental apparatus

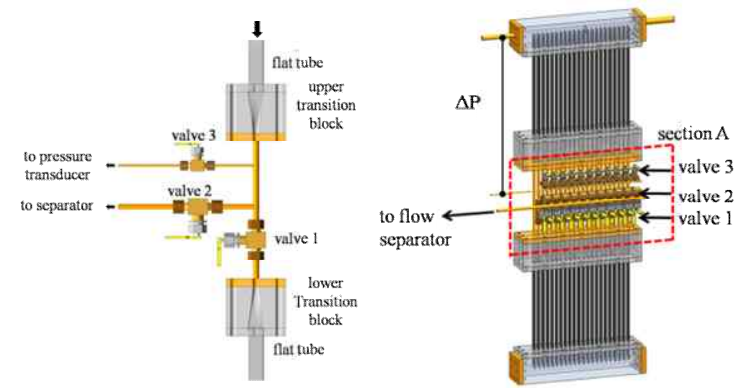

(Enlarged view of one channel of section A)

Figure3 Schematic illustrating of flow measurement principle installed underneath the header. Flat tubes were protruded to center of the header, which were secured using O-rings between the header and the aluminum plate. Two transition blocks were installed at the central part of the test section, which connected the flat tubes and the $6.0 \mathrm{~mm}$ I.D. round tubes (see Fig. 3). The round tubes served as flow measurement lines. Specially-made plate heaters having the same width and length with those of flat tubes were attached to every flat tubes. Thermal epoxy was applied between the tube and the heater, which were then tightly wrapped with nylon wire. The power to the heater was adjusted using a voltage transformer.

Before the refrigerant flowed into the test section, quality of the refrigerant was controlled at the pre-heater $(5 \mathrm{~kW}$ capacity) section by changing the power supply to the heater. The inlet quality is determined from the measured mass flow rate and supplied electric power as follows.

$$
x_{i}=\frac{1}{h_{\lg }}\left[\frac{Q_{p}}{m_{r}}-c_{p r}\left(T_{s a t}-T_{p, i}\right)\right]
$$

The refrigerant out of the test section was directed to a condenser, and the condensed refrigerant was pumped to the pre-heater. Mass flow rate was controlled by by-passing an appropriate amount of liquid from the magnetically coupled gear pump, and measured using a mass flow meter (Oval, CN101C-SS, 0 - $400 \mathrm{~kg} / \mathrm{hr}$ ) which was installed before the preheater. The branch channel flow rate was measured for every other channel (channel 2, 4, 6, 8, 10 for inlet pass, and channel $12,14,16,18,20,22,24,26$ for outlet pass) by directing the refrigerant to the flow measurement section. Channel was numbered from inlet of the header. As shown in Fig. 3, three manual valves - one at the main stream (valve 1), the other one at the bypass stream (valve 2) and the last one at the measurement line (valve 3 ) - were installed at every other channel. $1.0 \mathrm{~mm}$ inner diameter tube was used for valve 3 and $6.0 \mathrm{~mm}$ inner diameter tube was used for the other two valves. Normally, main stream valves (valve 1) were opened, and bypass stream valves (valve 2) were closed. To measure the flow rate at a certain channel, main stream valve was closed, and bypass valve was opened. Pressure measurement valves (valve 3) were open all the time. During the measurement, differential pressure between inlet of the lower header and Tjunction of the transition section was maintained the same by controlling the valve 2 in the transition section. The differential pressure was measured using a high precision pressure transducer (Setra, Model 230, 0 - $34 \mathrm{kPa}$ ).

The liquid and vapor fraction (quality) of the flow was thermally determined using a double tube heat exchanger. The tube-side refrigerant was condensed by cooling water flowing at the annular side. The double tube heat exchanger was divided into five sub-sections to cover a wide range of thermal loads from different channels. Temperatures were measured at four locations of the double tube heat exchanger; refrigerant temperatures at inlet and outlet of the tube, cooling water temperatures at inlet and outlet of the annulus. Thermo-wells having five thermocouples each were used to measure local temperatures. Two refrigerant pressures were also measured - 
one at the inlet of the heat exchanger, and the other at the outlet of the heat exchanger. The outlet refrigerant was maintained sub-cooled to insure sub-cooled flow into the flow meter. Vapor quality of each channel at the measurement location ' $\mathrm{x}$ ' is then determined from the heat balance between the refrigerant and cooling water. Channel inlet quality 'xin' is obtained by considering the heat added to the channel by plate heaters. Liquid or gas flow rate is determined from the channel inlet quality.

$$
\begin{gathered}
x=\left(h_{r, i}-h_{r, l}\right) / h_{\mathrm{lg}} \\
h_{r, i}=h_{r, o}+m_{w} c_{p w}\left(T_{w, o}-T_{w, i}\right) / m_{r} \\
x_{i n}=x-Q_{c h} / h_{\mathrm{lg}} \\
m_{l}=\left(1-x_{i n}\right) m_{r}, \quad m_{g}=x_{i n} m_{r}
\end{gathered}
$$

Here, $\mathrm{Q}_{\mathrm{ch}}$ is the heat added to the channel from inlet to measurement point. The refrigerant outlet enthalpy was determined from the measured temperature and pressure. The channel refrigerant flow rate was measured using a precision mass flow meter (Oval, CN003C-SS, $0-120 \mathrm{~kg} / \mathrm{hr}$ ). The water flow rate was measured by weighing the drained water. During the whole series of tests, several runs were made to check the repeatability of the data. The data were repeatable within $10 \%$. When the channel flow rates were added and compared with the supplied flow rate (for the channels where flow rates were not measured, the average values of the upstream and downstream channel flow rates were used), they agreed within $10 \%$. In this study, flow distribution data were presented as liquid flow ratio (LFR) or gas flow ratio (GFR), which is defined as the ratio of liquid or gas flow rate in each channel to the average values.

$$
L F R=\frac{m_{l}}{\sum m_{l} / N}, \quad G F R=\frac{m_{g}}{\sum m_{g} / N}
$$

For example, consider a inlet pass and assume that the total liquid and gas flow rate in the header is $1.0 \mathrm{~kg} / \mathrm{s}$ and $0.1 \mathrm{~kg} / \mathrm{s}$. Then, the average liquid and gas flow rate in each channel (for 5 measured channels in inlet pass) is $0.2 \mathrm{~kg} / \mathrm{s}$ and $0.02 \mathrm{~kg} / \mathrm{s}$. If the measured liquid and gas flow rate in the branch tube is 0.05 $\mathrm{kg} / \mathrm{s}$ and $0.02 \mathrm{~kg} / \mathrm{s}$, then the liquid flow ratio is 0.25 and the gas flow ratio is 1.0 .

\section{RESULTS AND DISCUSSION}

\section{General flow pattern and effect mass flux}

As stated earlier, inlet pass comprises 10 tubes and outlet pass comprises either 12(10/12) or 14(10/14) tubes. Channels were numbered from inlet of the header. Thus, inlet pass corresponds to channel 1 to 10 , and outlet pass corresponds to channel 11 to 22 (or 11 to 24 ). Refrigerant was supplied to the test section through a copper tube having smaller diameter (7.92 mm I.D.) than that of the

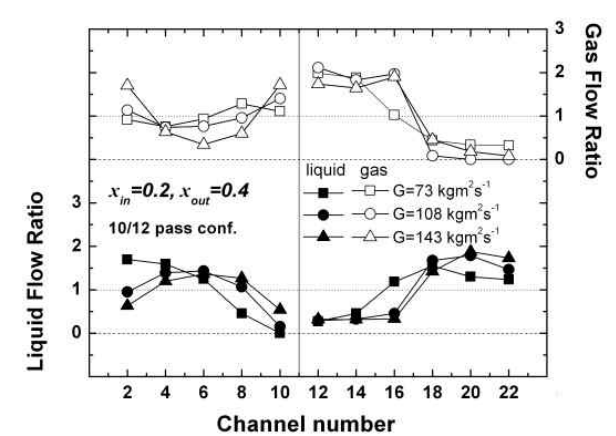

(a) Flow distribution data

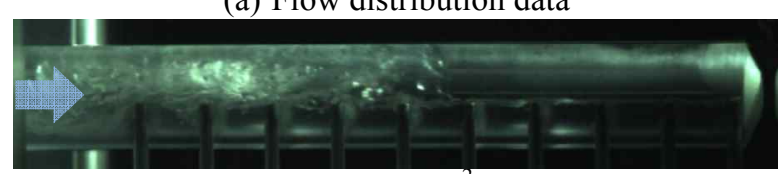

$\mathrm{G}=73 \mathrm{~kg} / \mathrm{m}^{2} \mathrm{~s}$

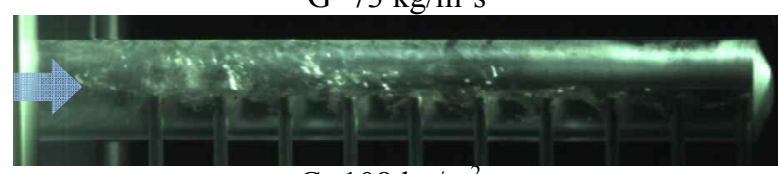

$\mathrm{G}=108 \mathrm{~kg} / \mathrm{m}^{2} \mathrm{~s}$

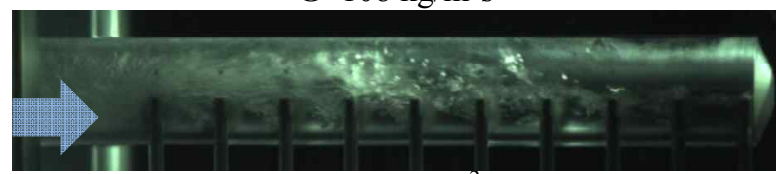

$\mathrm{G}=143 \mathrm{~kg} / \mathrm{m}^{2} \mathrm{~s}$

(b) Photos taken at inlet of upper header

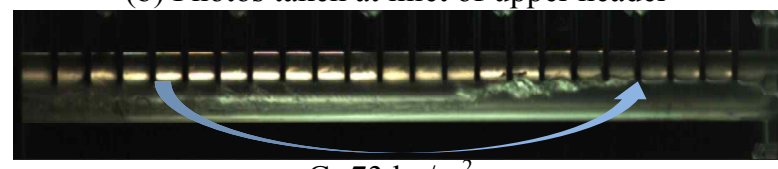

$\mathrm{G}=73 \mathrm{~kg} / \mathrm{m}^{2} \mathrm{~s}$

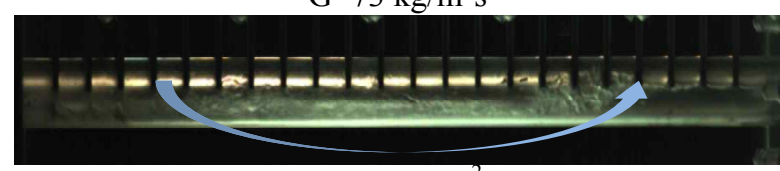

$\mathrm{G}=108 \mathrm{~kg} / \mathrm{m}^{2} \mathrm{~s}$

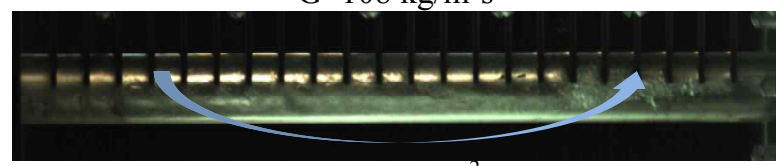

$\mathrm{G}=143 \mathrm{~kg} / \mathrm{m}^{2} \mathrm{~s}$

(c) Photos taken at combining/dividing header

Figure4 Flow distribution data and photos showing the effect of mass flux on flow distribution $\left(\mathrm{x}_{\text {out }}=0.4,10 / 12\right.$ configuration)

header (17 mm I.D.) and exited from the test section through a $11.1 \mathrm{~mm}$ I.D. copper tube. The refrigerant temperature at the test section was maintained at $10^{\circ} \mathrm{C}$. Heat was supplied to flat tubes through plate heaters. To prevent heat loss to the environment, the test section was heavily insulated. When the supplied heat was compared with the acquired heat calculated from the refrigerant enthalpy change, the supplied heat was approximately $5 \%$ larger than the acquired heat. The heat loss 
occurred from the headers (not insulted for flow visualization) and many copper tube lines at the transition section. Thus, acquired heat was used for the calculation of local quality. During the tests, the inlet quality $\left(\mathrm{x}_{\mathrm{in}}\right)$ was fixed at 0.2 . When inlet quality of the outlet pass $\left(\mathrm{x}_{\text {out }}\right)$ was 0.6 simulating a two pass configuration [see Fig. 1(b)], exit superheat was maintained at $5^{\circ} \mathrm{C}$. When $\mathrm{x}_{\text {out }}$ was 0.4 simulating a four pass configuration [see Fig. 1(c)], exit quality was maintained 0.6. The amount of heat to be supplied was determined considering the enthalpy difference and heat loss. It was assumed that same amount heat loss (approximately $5 \%$ of the supplied heat) occurred for both two pass [Fig. 1(b)] and four pass [Fig. 1(c)] configuration.

Fig. 4(a) shows the liquid and gas flow ratio at inlets of each (inlet and outlet) pass for 10 tube inlet and 12 tube outlet configuration (10/12). The inlet quality of the inlet pass is 0.2 and that of the outlet pass is 0.4 . For inlet pass, Fig. 4(a) shows that is forced downstream as mass flux increases. At $\mathrm{G}=60$ $\mathrm{kg} / \mathrm{m}^{2} \mathrm{~s}$, the liquid flow ratio of the second channel is 1.7 and that of the last channel is 0.1 . At $\mathrm{G}=120 \mathrm{~kg} / \mathrm{m}^{2} \mathrm{~s}$, the liquid flow ratio of the second channel increases to 0.6 and that of the last channel increases to 0.5 . The corresponding photos show that two-phase jet is supplied from the inlet tube, part of which hit the protruded tubes, and is deflected downward. Rest of the jet is delivered downstream bypassing protruded tubes. During the process, liquid film gets thicker along flow direction, reaching protruded tubes at a certain channel. From there on, the liquid level remains approximately the same. The actual flow, however, was quite unsteady. The liquid interface was wavy, and the liquid level changed intermittently. The still photo shown in the figure is a flow pattern just at one moment of the time. It was observed that liquid was intermittently sucked from the wavy interface. If the suction pressure at the inlet of the channel is large enough for the liquid suction from the interface, liquid is sucked into the channel. With the liquid in the channel, the suction pressure decreases. If the channel suction pressure is smaller than that needed for liquid suction, gas is sucked into the channel. With the gas in the channel, the suction pressure increases again sucking liquid into the channel. The process occurred repeatedly.

At the inlet pass, Two-phase mixture out of the inlet pass is first merged and then redistributed to the outlet pass in the lower combing/dividing header. For the outlet pass, Fig. 4(a) shows that liquid distribution is dependent on the mass flux. At a low mass flux of $73 \mathrm{~kg} / \mathrm{m}^{2} \mathrm{~s}$, more liquid is supplied into frontal channels and less liquid is supplied into downstream channels. As mass flux increases, more liquid is supplied into downstream channels. Accompanying photos in Fig. 4(c) show that two-phase jets exits the inlet pass, hit top of the header, and are deflected downstream along topside of the header forming a thin liquid film with lots of mists in the core flow. The liquid film gets thicker as it travels downstream by added two-phase jets. At the inlet of the outlet pass, the liquid film (and mists as well) is sucked into the tubes and gets thinner as it travels downstream until all the liquid is sucked into the channels. Photos in Fig. 4(c) show that liquid pool with clockwise recirculating flow is formed between protruded tubes. Liquid is also sucked into tubes from these liquid pools. As mass flux

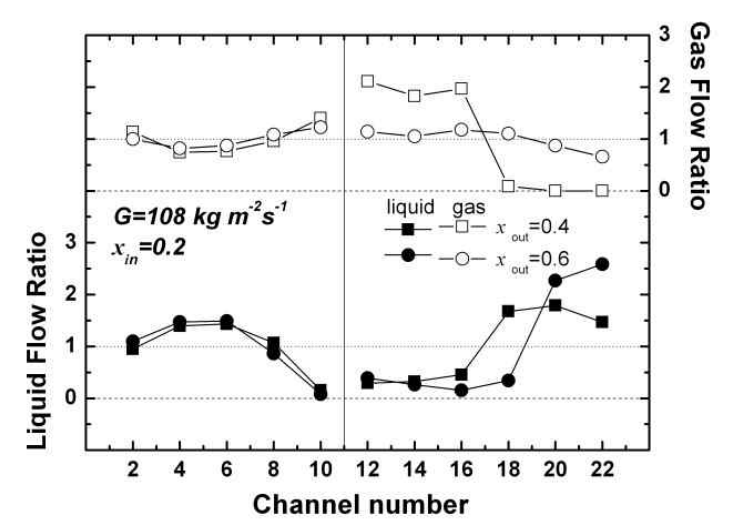

Figure 5 Flow distribution data showing the effect of vapour quality at outlet pass for (10/12 configuration)
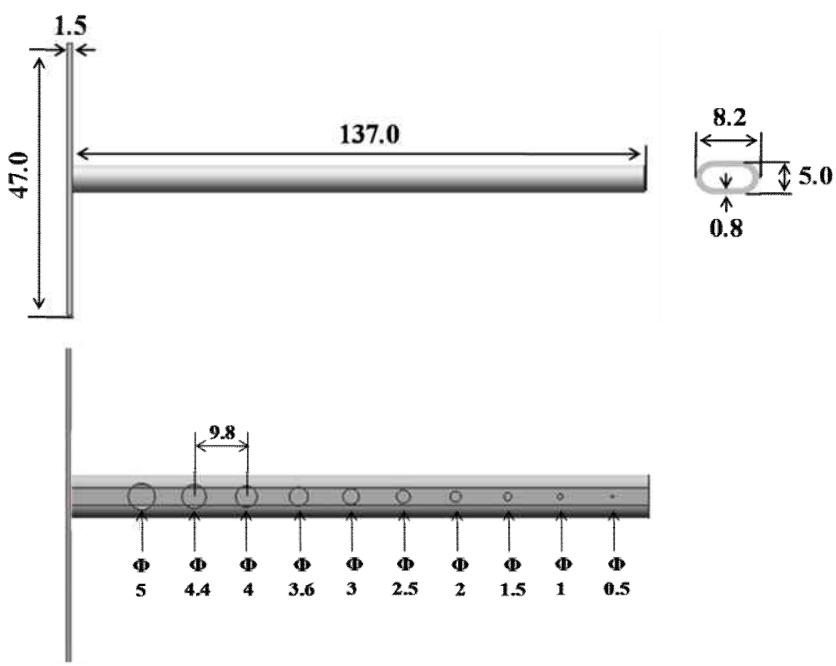

Figure 6 Insertion device used by Kim et al.[8] (unit : mm)

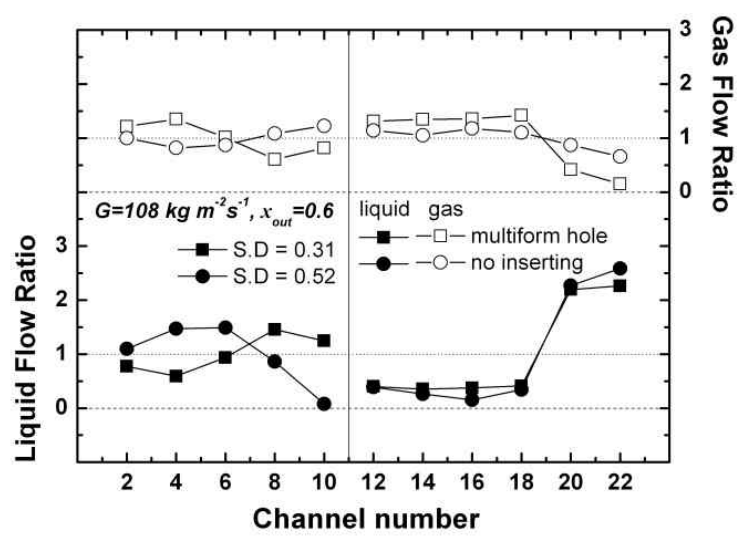

Figure 7 Effect of insertion device on flow distribution (10/12 configuration)

increases, the strength of two-phase jet out of the inlet pass increases as evident from Fig. 4(c), providing stronger axial momentum, which delivers the liquid film further downstream. Fig. 4 shows that gas distribution generally yields reversed trend to liquid distribution. It appears that combined effects of 
separated flow pattern and equal pressure drop constraint of each channel have yielded the reversed distribution between liquid and gas.

\section{Effect of vapour quality}

Fig. 5 shows the effect of vapor quality in the combing/dividing header $\left(\mathrm{x}_{\text {out }}\right)$ on liquid and gas flow ratio for $10 / 12$ configuration. Data are shown for two different mass flux $\left(\mathrm{G}=108 \mathrm{~kg} / \mathrm{m}^{2} \mathrm{~s}\right)$. At the inlet pass, the effect of $\mathrm{x}_{\text {out }}$ on liquid distribution is not significant. At the outlet pass, the effect of $\mathrm{x}_{\text {out }}$ is more evident. Liquid is forced downstream as $\mathrm{x}_{\text {out }}$ increases. As $\mathrm{x}_{\text {out }}$ increases, the strength of two-phase jet out of the inlet pass increases, providing stronger axial momentum, which delivers liquid further downstream.

\section{Effect of insertion device}

Kim et al. [8] has shown that refrigerant distribution in a parallel flow heat exchanger can be significantly improved by inserting a tube with small holes at the inlet of the header. The optimum hole geometry was dependent on the refrigerant flow direction. For the downward inlet pass of present study, multiform hole configuration shown in Fig. 6 has been suggested. Thus, tests were conducted with the tube inserted at inlet of the header. Representative results are shown in Fig. 7. These figures show that insertion device somewhat improve the flow distribution at the inlet pass, as is evident from the standard deviation (SD) of liquid flow ratio in the figure. Almost uniform distribution is obtained. At the outlet pass, however, the effect of insertion device on flow distribution is negligible. This suggests that, in the combining/dividing header, dividing characteristics of two-phase flow is not affected by the combining characteristics.

\section{Flow distribution correlations}

For two-phase flow distribution in a header/branch tube configuration, only limited models are available. Data and Majumdar [9] extended the single-phase model of Bajura and Jones [10] assuming a homogeneous two-phase flow. Ablanque et al. [11] adopted T-junction models by Seeger et al. [12] and Hwang et al. [13] to predict the phase spilt at header/branch tube junction. Tuo et al. [14] calculated the pressure drop at the header/branch junction using the experimentally determined pressure loss coefficient. All the above models require an iterative procedure, which satisfies equal pressure drop constraint along every header-channel-header pass, to obtain flow distribution in branch channels. In contrast, a simple correlating method was proposed by Watanabe et al. [15] from their upward branching study using R-11.They noted that fraction of liquid taken off by downstream channel can be correlated by the header gas Reynolds number at immediate upstream. Zou and Hrnjak [16] adopted the correlating method by Watanabe et al. [15], and proposed a correlation for parallel branching of R-134a from a vertical header.

Following the suggestion by Watanabe et al. [15], correlations were developed to predict the fraction of liquid or gas taken off by downstream channel. The correlations were developed through a multiple linear regression analysis. Commercial statistical package [17] was used to perform a multiple regression analysis, which provided the best fit of data. The accuracy of the correlation is evaluated using the " $\mathrm{R}$ squared" value. Higher $\mathrm{R}^{2}$ value implies better correlation. Two independent variables - header gas Reynolds number $\left(\mathrm{Re}_{\mathrm{g}}\right)$ and ratio of inlet and outlet channel number (CR) - were chosen. Separate correlations were developed for inlet and outlet pass. One thing to note is that liquid and gas flow rate at odd numbered channels are obtained by interpolating those of the even numbered channels, because flow rates were measured only at even numbered channels. Listed below are the correlations.

$$
\begin{aligned}
& \text { Inlet pass }: \frac{\dot{m}_{T l, i}}{\dot{m}_{H l, i}}=469.1 \mathrm{Re}_{g}{ }^{-0.75} C R^{0.71} \quad \text { (liquid), } \\
& \frac{\dot{m}_{T g, i}}{\dot{m}_{H g, i}}=3652 \mathrm{Re}_{g}{ }^{-1.02} C R^{1.22} \text { (gas) (7) } \\
& \text { Outlet pass }: \frac{\dot{m}_{T l, i}}{\dot{m}_{H l, i}}=5.21 \mathrm{Re}_{g}{ }^{-0.44} C R^{-2.33} \quad \text { (liquid), } \\
& \\
& \frac{\dot{m}_{T g, i}}{\dot{m}_{H g, i}}=6.4 \mathrm{Re}_{g}{ }^{-0.34} C R^{-0.26} \text { (gas)(8) }
\end{aligned}
$$

The above discussion suggests that the present correlation has limited applicability, which is understandable from the fact that only limited data as well as limited variables [gas Reynolds number, ratio of inlet and outlet channel number (CR)] were used for development of the correlation. More data are necessary, which account for the effect of geometric variables (non-dimensional tube protrusion depth, header/branch tube diameter ratio, header/branch tube flow area ratio, header shape, etc.) as well as operating variables (mass flux, quality, temperature, etc.). Refined correlation should consider both geometric and operating variables.

\section{CONCLUSIONS}

Refrigerant R-410A flow distributions were experimentally studied for a two pass evaporator with upper horizontal combining-dividing header simulating a brazed aluminum heat exchanger. Two different pass ratios (10/12 and 10/14) were investigated. Tests were conducted flow for the mass flux from 73 to $143 \mathrm{~kg} / \mathrm{m}^{2} \mathrm{~s}$ and quality $\left(\mathrm{x}_{\text {out }}\right.$ ) from 0.4 to 0.6 . Listed below are major conclusions.

(1) In the combining/dividing header, two-phase mixture from the inlet pass is first merged and then re-distributed to the outlet pass. More liquid is forced downstream as header mass flux or quality increases yielding better flow distribution (or smaller heat transfer degradation). 
(2) The difference in the ratio of inlet and outlet channel number $(10 / 12$ and 10/14) does not significantly affect the flow distribution.

(3) With the insertion device installed in the inlet header, flow distribution at the inlet pass is significantly improved. However, at the outlet pass, the effect of insertion device is negligible.

(4) Correlations are developed to predict the fraction of liquid or gas taken off by downstream or upstream channel as a function of header gas Reynolds number and ratio of inlet and outlet channel number.

\section{REFERENCES}

[1] Kulkarni T., Bullard C.W., Cho K., Header design tradeoffs in microchannel evaporators, Applied Thermal Engineering, Vol. 24, 2004, pp. 759-776

[2] Webb R.L., Chung K., Two-phase flow distribution in tubes of parallel flow heat exchangers, Heat Transfer Engineering, Vol. 26, 2004, pp. 3-18

[3] Hrnjak P.S., Flow distribution issues in parallel flow heat exchangers, ASHRAE Annual Meeting, AN-04-1-2, 2004

[4] Lee S.-Y., Flow distribution behaviour in condensers and evaporators, Proceedings of the 13th International Heat Transfer Conference, KN-08, Sydney, Australia, 2006

[5] Ahmad M., Berthoud G., Mercier P., General characteristics of two-phase flow distribution in a compact heat exchanger, Int. J. Heat Mass Transfer, Vol. 52, 2009, pp. 442-450

[6] Kim N.-H., Kim D.-Y., Byun H.-W., Effect of inlet configuration on the refrigerant distribution in a parallel flow heat exchanger header, Int. J. Ref., Vol. 34, 2011, pp. 1209-1221

[7] Kim N.-H., Byun H.-W., Effect of inlet configuration on upward branching of two-phase refrigerant in parallel flow heat exchanger, Int. J. Ref., Vol. 36, 2013, pp. 1062-1077

[8] Kim N.-H., Lee E.-J., Byun H.-W., Improvement of two-phase refrigerant distribution in a parallel flow minichannel heat exchanger using insertion devices, Applied Thermal Engineering, Vol. 59, 2013, pp. 116-130

[9] Data A.B., Majumdar A.K., A calculation procedure for two phase flow distribution in manifolds with and without heat transfer, Int. J. Heat Mass Transfer, Vol. 26, 1983, pp. 1321-1328

[10] Bajura R.A., Jones E.H., Flow distribution manifolds, Journal of Fluids Eng. Vol. 98, 1976, pp. 654-665

[11] Ablanque N., Oliet C., Rigola J., Perez-Segarra C.D., Oliva A., Two-phase flow distribution in multiple parallel tubes, Int. J. Thermal Sci., Vol. 49, 2010, pp. 909-921

[12] Seeger W., Reimann J., Muller U., Two-phase flow in a Tjunction with a horizontal inlet, part 1: phase saparation, Int. J. Multiphase Flow, Vol. 12, pp. 1986, pp. 575-585

[13] Hwang S.T., Soliman H.M., Lahey R.T., Phase separation in dividing two-phase flow, Int. J. Multiphase Flow, Vol. 14, pp. 1998, pp. $439-458$

[14] Tuo H., Bielskus A., Hrnjak P., An experimentally validated modeling of refrigerant distribution in a parallel microchannel evaporator, ASHRAE Trans. 118, 2012, pp. CH-12-C-48

[15] Watanabe M., Katsuda M., Nagata K., Two-phase flow distribution in multi-pass tube modeling serpentine type evaporator, ASME/JSME Thermal Engineering Conf., 2, 1995, pp. 35-42

[16] Zou Y., Hrnjak P., Experiment and visualization on R-134a upward flow in the vertical header of microchannel heat exchanger and its effect on distribution, Int. J. Heat Mass Transfer, Vol. 62, 2013, pp. 124-134
[17] Datafit, Oakdale Engineering, http://www.oakdaleengr.com/, Version 8.21996 